\title{
Combination of Continuous Dexmedetomidine Infusion with Titrated Ultra-Low-Dose Propofol-Fentanyl for an Awake Craniotomy Case report
}

Samaresh Das, ${ }^{1}$ Ali Al-Mashani, ${ }^{2}$ Neelam Suri, ${ }^{1}$ Neeraj Salhotra, ${ }^{2}$ *Nilay Chatterjee ${ }^{1}$

$$
\begin{aligned}
& \text { مزيج من الدكسميديتوميدين (بالجرعة المستمرة) مع جرعة مخفضة ومعيَّة من } \\
& \text { الفنتانيل و البروبوفول في عملية حج القحف والمريض في وعيه } \\
& \text { تقرير حالة }
\end{aligned}
$$

سامارش داس، علي المعشني، نيلام سوري، نيراج سالوترا، نيلوي تشاترجي

\begin{abstract}
An awake craniotomy is a continuously evolving technique used for the resection of brain tumours from the eloquent cortex. We report a 29-year-old male patient who presented to the Khoula Hospital, Muscat, Oman, in 2016 with a two month history of headaches and convulsions due to a space-occupying brain lesion in close proximity with the left motor cortex. An awake craniotomy was conducted using a scalp block, continuous dexmedetomidine infusion and a titrated ultra-low-dose of propofol-fentanyl. The patient remained comfortable throughout the procedure and the intraoperative neuropsychological tests, brain mapping and tumour resection were successful. This case report suggests that dexmedetomidine in combination with titrated ultra-low-dose propofolfentanyl are effective options during an awake craniotomy, ensuring optimum sedation, minimal disinhibition and a rapid recovery. To the best of the authors' knowledge, this is the first awake craniotomy conducted successfully in Oman.
\end{abstract}

Keywords: Anesthesia; Craniotomy; Dexmedetomidine; Propofol; Fentanyl; Case Report; Oman.

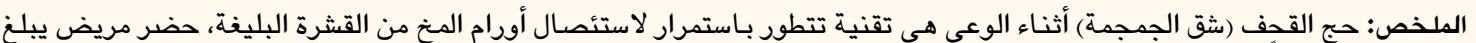

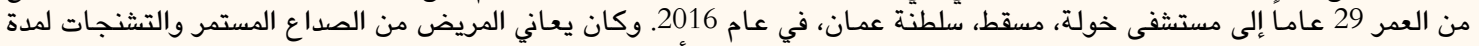

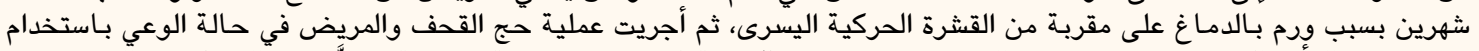

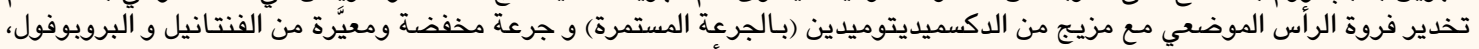

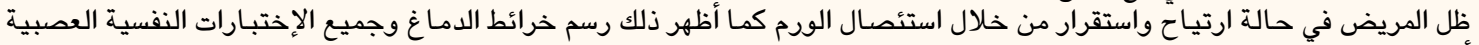

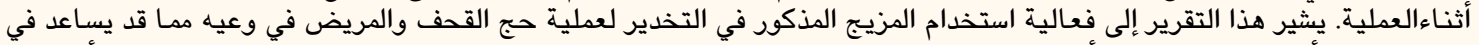

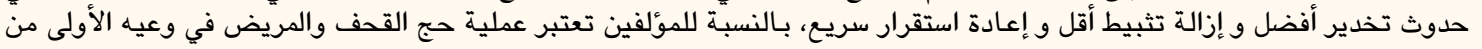
نوعها في سلطنة عمان.

$$
\text { كلمات مفتاحية: التخدير؛ حج القحف؛ الديكسميديتوميدين؛ البروبوفول؛ الفنتانيل؛ تقرير حالة؛ عُمان. }
$$

A N AWAKE CRANIOTOMY IS A PROCEDURE used for the resection of brain tumours from the eloquent cortex and during surgeries for epilepsy and movement disorders. ${ }^{1}$ This technique is also used for the management of aneurysms and arteriovenous malformations near key areas of the brain, such as areas responsible for movement, language, sensation, vision, hearing, thought processing, fine motor skills and coordination. The principal advantage of this technique is that it permits lesion removal without compromising the functional integrity of the brain by damaging the eloquent cortex, therefore resulting in enhanced neurological recovery. ${ }^{1}$
Growing evidence also indicates that there are greater survival benefits associated with an awake craniotomy. ${ }^{2}$ Other advantages include shorter intensive care unit (ICU) and overall hospital stays, a decreased incidence of postoperative complications such as nausea and vomiting and significantly reduced cost of care. ${ }^{3}$

\section{Case Report}

A 29-year-old man presented to the Khoula Hospital, Muscat, Oman, in 2016 with a two month history of headaches and convulsions. He had initially been managed at a peripheral hospital where a computed 


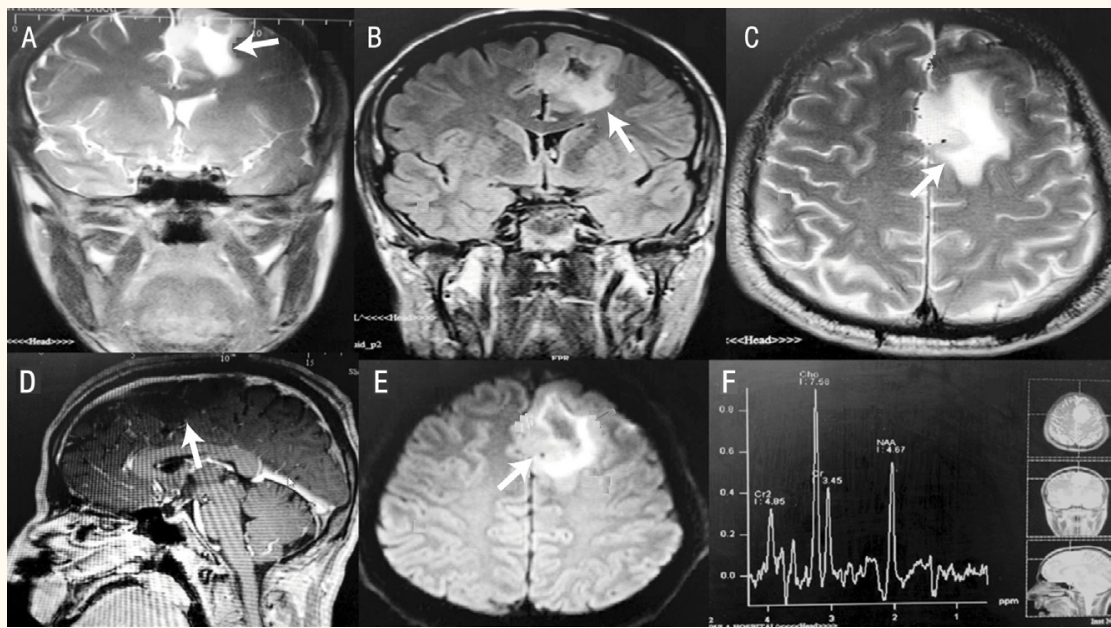

Figure 1A-F: Magnetic resonance imaging (MRI) of a patient with headaches and convulsions due to a space-occupying brain lesion. A: Coronal T2-weighted MRI showing a hyperintense left frontal intra-axial space-occupying lesion in the left superior frontal gyrus surrounded by oedema (arrow). B: Coronal fluid-attenuated inversion recovery MRI showing peripheral hyperintensity around the lesion (arrow). C: Axial T2-weighted MRI showing the lesion (arrow). D: Sagittal post-contrast MRI showing the non-contrast enhancing lesion in the left frontal lobe approaching the motor cortex (arrow). E: Diffusion-weighted MRI showing peripheral diffusion restriction of the lesion (arrow). F: MRI spectroscopy showing decreased $\mathrm{N}$-acetylaspartate and enhanced choline peaks, indicating a high-grade tumour.

tomography scan of the brain revealed a left frontoparietal parafalcine lesion measuring $3.7 \times 3.6 \times 3.0 \mathrm{~cm}$. He was prescribed antiepileptics including dexamethasone and referred to the Khoula Hospital, a tertiary care neurosurgical centre. Before referral, the patient had multiple episodes of left-sided jerky movements in his upper limbs.

Magnetic resonance imaging revealed a left cortical-subcortical frontal gyrus lesion surrounded by oedema with peripheral diffusion restriction. The lesion reached the premotor cortex and was in close proximity with the motor cortex, although it did not affect the left precentral gyrus [Figure 1]. Considering the critical location of the lesion, an awake craniotomy was scheduled. The patient was counselled by both a neurosurgeon and neuroanaesthesiologists and given a detailed explanation of the procedure, including the benefits and associated risks and the need for intraoperative neuropsychological testing. He was reassured that any complications arising during the procedure would be addressed immediately. During the pre-anaesthetic check-up, the patient's airway was assessed and the results of previous investigations were reviewed. Anticonvulsants and dexamethasone were continued as previously prescribed and $7.5 \mathrm{mg}$ of midazolam was administered orally the night before the procedure.

On the day of the surgery, $4 \mathrm{mg}$ of ondansetron, $40 \mathrm{mg}$ of pantoprazole and $7.5 \mathrm{mg}$ of midazolam were administered to the patient at $6 \mathrm{AM}$. After the patient was transferred to the operating theatre, a $16 \mathrm{G}$ intravenous cannula and a $20 \mathrm{G}$ arterial cannula in the left radial artery were placed under local anaesthesia. Standard monitoring as recommended by the American Society of Anesthesiologists was initiated. ${ }^{4}$ Dexmedetomidine was infused $(1 \mu \mathrm{g} / \mathrm{kg}$ over the first 10 minutes as a loading dose followed by $0.5 \mu \mathrm{g} / \mathrm{kg} / \mathrm{hour}$ ), along with propofol (50 $\mathrm{\mu g} / \mathrm{kg} /$ minute) and fentanyl $(0.01 \mu \mathrm{g} / \mathrm{kg} /$ minute). The patient was oxygenated through a face mask (4 L/minute) and end-tidal carbon dioxide was monitored by attaching the sampling tube to the inner surface of the mask. The propofol and dexmedetomidine infusions were adjusted to maintain a Ramsay Sedation Scale score of between 2-3. A scalp block was applied bilaterally, targeting the nerves supplying the scalp (e.g. the supratrochlear, supraorbital, zygomaticotemporal, auriculotemporal, great auricular and greater and lesser occipital nerves). Approximately $2-3 \mathrm{~mL}$ of $0.25 \%$ bupivacaine was used for each nerve. The head was positioned and fixed using skull pins (MAYFIELD ${ }^{\circledR}$ Skull Pins, Integra LifeSciences Corp., Plainsboro, New Jersey, USA) applied 15 minutes after the scalp block. Surgical drapes were adjusted so as to maintain easy access to the patient's airway. Considering the patient's cooperation and level of tolerance, it was decided that he would be kept awake throughout the craniotomy. An emergency plan was formulated to secure the patient's airway with a laryngeal mask airway device (LMA ProSeal ${ }^{\mathrm{TM}}$, Teleflex ${ }^{\circledR}$ Incorporated, Wayne, Pennsylvania, USA), if needed. Before starting the surgery, the dura was infiltrated with $10 \mathrm{~mL}$ of $2 \%$ lignocaine.

The dura incision was made [Figure 2A] without the patient complaining of pain. Upon opening the dura, increased intracranial pressure was 


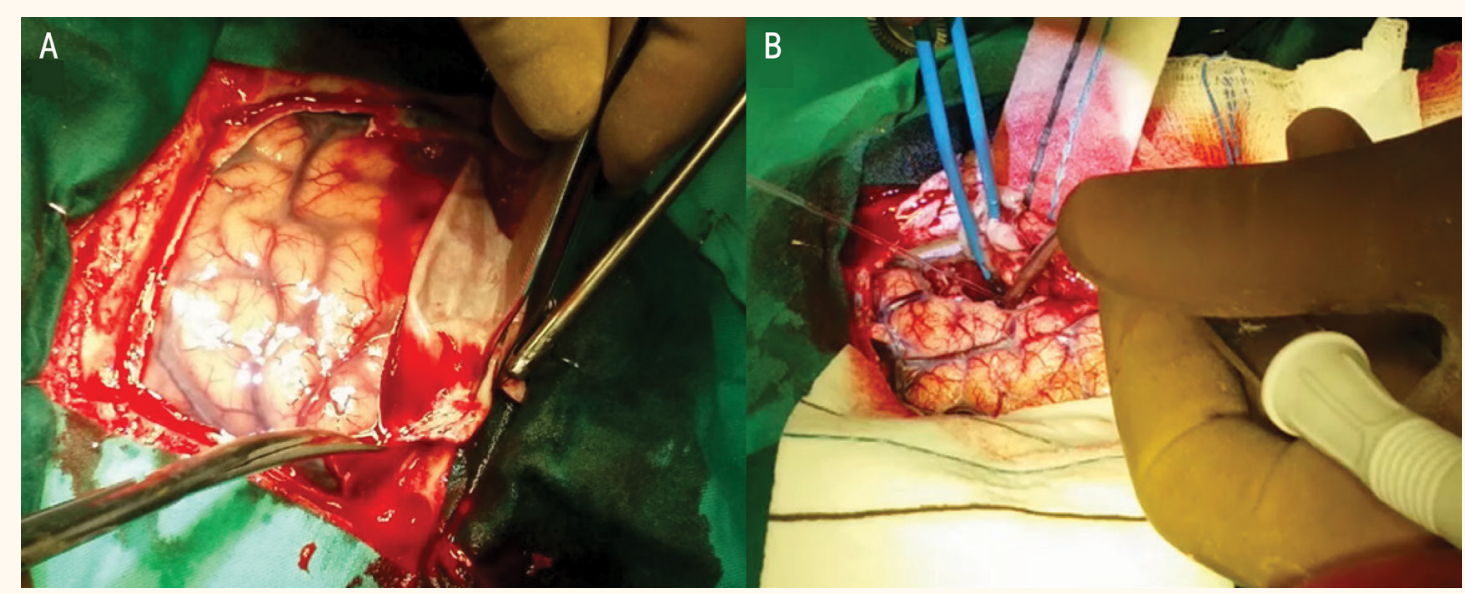

Figure 2A \& B: Photographs of an awake craniotomy performed on a patient with a space-occupying brain lesion showing the (A) opening of the dura and (B) resection of the tumour.

observed; this was managed with mannitol $(0.5 \mathrm{~g} / \mathrm{kg})$ and frusemide $(10 \mathrm{mg})$. The propofol and fentanyl infusions were then stopped and the patient was woken completely. Supplemental doses of anticonvulsants and ondansetron were administered. Neuropsychological tests were carried out to check the patient's motor functions, orientation, memory, attention, articulation, ability to name pictures and objects, read and repeat words and perform arithmetic calculations. Additionally, brain mapping by direct electrical stimulation using bipolar electrodes was performed. The patient remained completely awake, cooperative and responsive. The tumour was excised [Figure 2B] and cortical mapping ensued. Throughout the surgery, the patient remained haemodynamically stable and was able to follow verbal commands and communicate effectively. The dexmedetomidine infusion $(0.5 \mu \mathrm{g} / \mathrm{kg} /$ hour $)$ was continued throughout the procedure.

After completing the tumour resection, propofol and fentanyl infusions were initiated once again and the sedation was increased. Following the closure of the skin incision, all infusions of sedatives were discontinued and the patient was transferred to the ICU for observation. Postoperatively, the patient exhibited no neurological deficits and his ICU stay was uneventful. The patient was transferred to a normal ward the following morning and was discharged on the fourth postoperative day. Histopathological analysis of the lesion revealed it to be an astrocytoma (World Health Organization grade II). ${ }^{5}$

\section{Discussion}

The anaesthetic considerations required for an awake craniotomy are challenging. Careful patient selection, preoperative preparation and effective communication between the neuroanaesthetist, neurosurgeon and patient are key. ${ }^{3}$ During awake craniotomies, patients do not always remain awake throughout the course of the entire surgery. Varying levels of sedation or anaesthesia are needed for certain parts of the procedure, such as during the scalp incision, craniotomy or opening of the dura. ${ }^{3}$ Depending on the anaesthetist's preference and the extent of the patient's understanding and cooperation, either an "awake throughout" or "asleep/awake and asleep" technique is selected. In the former technique, only sedation and analgaesia are used, whereas the latter includes general anaesthesia and involves securing the airway with a laryngeal mask airway device during the initial "asleep" phase. ${ }^{3}$ However, regardless of technique, the patient must be completely awake during the brain mapping and neuropsychological tests. Thereafter, the patient can either be kept awake or re-anesthetised depending on the situation. A scalp block is frequently used for pain relief in both types of awake craniotomy techniques. ${ }^{3}$ To the best of the authors' knowledge, this case reports the first awake craniotomy conducted successfully in Oman.

The most commonly used anaesthetic agents for an awake craniotomy are propofol, opioids and dexmedetomidine. An infusion of propofol supplemented with an opioid is the most frequently used combination, as it improves the quality of the analgaesia and reduces hypnotic requirements. ${ }^{3,6-8}$ Gignac et al. found no difference in operative conditions, electrocorticography findings and stimulation testing results when comparing various opioids. ${ }^{9}$ In another study, both intermittent fentanyl and continuous remifentanil infusions resulted in similar rates of patient satisfaction, recall and intraoperative complications. ${ }^{10}$ Overall, these opioids seem to be equally efficacious for awake craniotomies. ${ }^{6}$ Increasingly, the $\alpha_{2}$ agonist dexmedetomidine is used in awake craniotomies due to its unique sedative, 
analgaesic and anxiolytic properties and because of its minimal effects on ventilation. ${ }^{7}$ Dexmedetomidine reduces opioid requirements by $30-50 \%$, is not associated with disinhibition-a common problem with propofol and benzodiazepines - and has minimal effects on electrocorticography. ${ }^{7}$ However, no research is as yet available to make a direct comparison between propofol-opioids and dexmedetomidine for awake craniotomies. In the current case, a constant infusion of dexmedetomidine and an ultra-low-dose infusion of propofol-fentanyl were used to ensure optimum sedation, minimal disinhibition and a rapid recovery. The propofol-fentanyl infusions were halted after the dura was opened to allow the patient sufficient time to emerge from sedation and undergo intraoperative testing; the necessary amount of time has been reported to be approximately nine minutes with such combinations. ${ }^{11}$ The principal advantages of this combination are that the propofol-fentanyl can be titrated for the individual's specific physiological requirements to maintain sleep and that it can be terminated before brain mapping; in addition, it can be reinitiated to deepen sedation or to induce a second sleep phase if needed. ${ }^{11}$

Neuropsychological tests and cortical mapping are critical steps during an awake craniotomy. ${ }^{3}$ During this stage, the patient is awoken if asleep beforehand and is allowed to gradually adjust to the environment before clinical evaluation. Emergence from sedation can cause several complications, such as pain and discomfort, agitation, nausea and vomiting. ${ }^{3}$ If any of these occur, they should be addressed immediately before they lead to poor surgical conditions. The objective of cortical stimulation or brain mapping is to localise the eloquent areas of the brain-the areas involved in speech and language comprehensionand the motor and sensory cortex through direct electrical stimulation of the cerebral cortex. ${ }^{8}$ If there are any alterations in the patient's speech, language or motor function during electrical stimulation, the neurosurgeon is immediately notified. ${ }^{12}$ Once the cortex has been mapped functionally, resection of the lesion continues.

During cortical mapping, focal or generalised seizures have been reported to occur in up to $16 \%$ of patients undergoing craniotomies with conscious sedation. ${ }^{13}$ These are usually managed by irrigating the brain tissue with ice-cold saline; seizures which do not respond to ice-cold saline are treated with benzodiazepines, anti-epileptics or sedation with control of the airway. ${ }^{6}$ The anaesthetist should always have an emergency plan for airway control, keeping in mind that securing the airway in a patient whose head is fixed in place with skull pins can be extremely challenging. The ProSeal ${ }^{\mathrm{TM}}$ laryngeal mask airway device (Teleflex ${ }^{\circledR}$ Incorporated) is an optimal choice in this context. ${ }^{8}$ Intolerance to the awake craniotomy procedure on the part of the patient is the most frequently encountered complication, commonly due to prolonged or improper positioning, the presence of a urinary catheter or the occurrence of intraoperative seizures. ${ }^{8}$ Other known intraoperative adverse events include hypoventilation, hypoxia, hypercapnia, hypoor hypertension, brady- or tachycardia, brain swelling, anxiety, agitation or fatigue..$^{14,15}$

\section{Conclusion}

An awake craniotomy is a well-tolerated procedure with few inherent complications. This case report describes a successful awake craniotomy using continuous dexmedetomidine combined with ultralow-dose titrated propofol-fentanyl infusions. This effective combination allows for the rapid titration of the sedative to desired levels during the initial part of the surgery and the discontinuance of the propofol-fentanyl infusion thereafter in order to allow the patient to wake up rapidly for intraoperative neuropsychological tests and cortical mapping.

\section{References}

1. Ghazanwy M, Chakrabarti R, Tewari A, Sinha A. Awake craniotomy: A qualitative review and future challenges. Saudi J Anaesth 2014; 8:529-39. doi: 10.4103/1658-354X.140890.

2. Yordanova YN, Moritz-Gasser S, Duffau H. Awake surgery for WHO grade II gliomas within "noneloquent" areas in the left dominant hemisphere: Toward a "supratotal" resection - Clinical article. J Neurosurg 2011; 115:232-9. doi: 10.3171/2011.3.JNS101333.

3. Burnard C, Sebastian J. Anaesthesia for awake craniotomy. Contin Educ Anaesth Crit Care Pain 2013; 14:6-11. doi: 10. 1093/bjaceaccp/mkt024.

4. American Society of Anesthesiologists. Standards and guidelines. From: www.asahq.org/quality-and-practice-manage ment/standards-and-guidelines Accessed: April 2016.

5. Louis DN, Perry A, Reifenberger G, von Deimling A, Figarella-Branger D, Cavenee WK, et al. The 2016 World Health Organization Classification of Tumors of the Central Nervous System: A summary. Acta Neuropathol 2016; 131:803-20. doi: 10.1007/s00401-016-1545-1.

6. Chui J. Anesthesia for awake craniotomy: An update. Rev Colomb Anestesiol 2015; 43:22-8. doi: 10.1016/j.rcae.2014. 07.003 .

7. Bekker A, Sturaitis MK. Dexmedetomidine for neurological surgery. Neurosurgery 2005; 57:1-10. doi: 10.1227/01.neu.0000 163476.42034.a1

8. Brydges G, Atkinson R, Perry MJ, Hurst D, Laqua T, Wiemers J. Awake craniotomy: A practice overview. AANA J 2012; 80:61-8.

9. Gignac E, Manninen PH, Gelb AW. Comparison of fentanyl, sufentanil and alfentanil during awake craniotomy for epilepsy. Can J Anaesth 1993; 40:421-4. doi: 10.1007/BF03009510. 
10. Manninen PH, Balki M, Lukitto K, Bernstein M. Patient satisfaction with awake craniotomy for tumor surgery: A comparison of remifentanil and fentanyl in conjunction with propofol. Anesth Analg 2006; 102:237-42. doi: 10.1213/01. ANE.0000181287.86811.5C.

11. Keifer JC, Dentchev D, Little K, Warner DS, Friedman AH, Borel CO. A retrospective analysis of a remifentanil/propofol general anesthetic for craniotomy before awake functional brain mapping. Anesth Analg 2005; 101:502-8. doi: 10.1213/01. ANE.0000160533.51420.44.

12. Pereira LC, Olivira KM, L'Abbate GL, Sugai R, Ferreira JA, da Motta LA. Outcome of fully awake craniotomy for lesions near the eloquent cortex: Analysis of a prospective surgica series of 79 supratentorial primary brain tumors with long follow-up. Acta Neurochir (Wien) 2009; 151:1215-30. doi: 10.1007/s00701-009-0363-9.
13. Archer DP, McKenna JM, Morin L, Ravussin P. Conscioussedation analgesia during craniotomy for intractable epilepsy: A review of 354 consecutive cases. Can J Anaesth 1988; 35:338-44. doi: 10.1007/BF03010852.

14. Olsen KS. The asleep-awake technique using propofolremifentanil anaesthesia for awake craniotomy for cerebral tumours. Eur J Anaesthesiol 2008; 25:662-9. doi: 10.1017/ S0265021508003633.

15. Lobo F, Beiras A. Propofol and remifentanil effect-site concentrations estimated by pharmacokinetic simulation and bispectral index monitoring during craniotomy with intraoperative awakening for brain tumor resection. J Neurosurg Anesthesiol 2007; 19:183-9. doi: 10.1097/ANA. ob013e31805f66ad. 